\title{
The composition of solid solutions crystallising from aqueous solutions: the influence of supersaturation and growth mechanisms
}

\author{
Carlos M. Pina*, Michael Enders, Andrew Putnis \\ Institut für Mineralogie, Universität Münster, Corrensstraße 24, D-48149 Münster, Germany
}

\begin{abstract}
In this paper we present a new approach to the problem of the crystallisation in solid solution-aqueous solution (SS-AS) systems, in which two main controlling factors have been considered: (i) the supersaturation state of the multicomponent solution in contact with the growing crystal and (ii) the growth mechanisms, operating at a molecular scale on the various faces of the crystal. Supersaturation has been evaluated as a function of the solid solution (the $\beta$ function) and the transitional supersaturation between spiral growth and two dimensional nucleation mechanisms has been considered as a linear function of the solid composition (the $\beta^{*}$ line). By superimposing $\beta$ functions and $\beta^{*}$ line on a supersaturation-solid composition diagram, we can define compositional regions growing according to different growth mechanisms. In order to test our model, a number of in situ Atomic Force Microscope (AFM) experiments have been conducted in the $\mathrm{Ba}^{2+}-\mathrm{Sr}^{2+}-\mathrm{SO}_{4}^{2-}-\mathrm{H}_{2} \mathrm{O}$ system, using barite (001) as the substrate. The general growth behaviour observed is consistent with the predictions given for a number of initial aqueous solution compositions. Microprobe analysis shows that the new (001) layers grown under conditions where the maximum supersaturation corresponded to intermediate compositions of the $\left(\mathrm{Ba}, \mathrm{Sr}_{2} \mathrm{SO}_{4}\right.$ solid are very Sr-rich. A qualitative explanation for such a compositional shift is given on the basis of nucleation rate calculations in the $\mathrm{Ba}^{2+}-\mathrm{Sr}^{2+}-\mathrm{SO}_{4}^{2-}-\mathrm{H}_{2} \mathrm{O}$ system. Finally we discuss the effect of the substrate on the formation and distribution of two-dimensional $(\mathrm{Ba}, \mathrm{Sr}) \mathrm{SO}_{4}$ nuclei on a barite (001) surface. (C) 2000 Elsevier Science B.V. All rights reserved.
\end{abstract}

Keywords: Supersaturation; Growth mechanisms; Solid solution; Barite; Atomic Force Microsocopy

\section{Introduction}

One of the key issues in geochemistry is the determination and interpretation of the chemical composition of solid solutions crystallising from aqueous solutions. By quantifying the distribution

\footnotetext{
* Corresponding author. Fax: +49-2-51-83-383-97.

E-mail address: pina@nwz.uni-muenster.de (C.M. Pina).
}

coefficients between minerals and the fluids from which they crystallised, physicochemistry, hydrology and climatic conditions of actual and ancient natural environments can be inferred (Pingitore, 1978; Delaney and Boyle, 1987). Furthermore, the particular case of metal ion partitioning during the crystallisation of many minerals (for example, the incorporation of heavy and radioactive metals in sulphates and carbonates) is of great relevance when dealing with 
problems of industrial contamination of ground-water (Dudley et al., 1988; Zachara et al., 1991). The emphasis in much of the recent literature on metal sorption on mineral surfaces has been on trying to determine the processes by which metal-ion uptake occurs, and differentiating processes such as adsorption and surface precipitation (Sposito, 1986; Davis et al., 1987; Zachara et al., 1991; Tesoriero and Pankow, 1996).

Clearly, a prerequisite for studies on co-precipitation and sorption is the ability to determine the saturation state of a given aqueous solution relative to the whole range of compositions of the relevant solid solution, but the current computer codes available such as MINTEQA2 (Allison et al., 1991) can only describe end-member compositions. We demonstrate here that in order to understand the crystallisation behaviour in solid solution-aqueous solution (SS-AS) systems, the saturation state of a given aqueous solution must be calculated with respect to all compositions of the solid solution. It is possible, for example, for a given aqueous solution to be undersaturated with respect to both end members of a binary solid solution, and yet supersaturated with respect to some intermediate composition. This emphasises the importance of having a valid method for mathematically describing such systems (Prieto et al., 1997; Putnis et al., 1997).

Thermodynamic approaches to crystal/fluid partitioning have provided an important theoretical framework (Drake and Holloway, 1978; Sverjensky,1985; Blundy and Wood, 1994), but their utility is limited to conditions near equilibrium. In many cases, crystallisation takes place at moderate to high degrees of supersaturation (Goldsmith, 1959; Kastner and Siever, 1979; Broecker and Peng, 1982). Under supersaturated conditions ionic transport in the solution and mechanisms of growth unit incorporation at the interface strongly determine growth face advance rates and affect crystallisation behaviour as well as the composition of the solid (Lorens, 1980; Putnis et al., 1992; Paquette and Reeder, 1994; Prieto et al., 1997). Thus, the actual ionic distribution is essentially controlled by the interrelation between two main factors: (i) the supersaturation state of the multicomponent solution in contact with the growing crystal and (ii) the growth mechanisms, operating at a molecular scale on the various faces of the crystal.
Here we present a new approach to the problem of ion partitioning during crystallisation in SS-AS systems. We first determine the supersaturation state of a given aqueous solution as a function of the solid solution composition ( $\beta$ function) and, second, we relate the supersaturation to the possible operating growth mechanisms (e.g. spiral growth or two-dimensional nucleation) of different solid compositions. This is done by relating the $\beta$ functions for various aqueous solution compositions to the line which describes how the boundary between the spiral growth and two-dimensional nucleation mechanisms varies with the solid composition (i.e., the transitional supersaturation $\beta^{*}$ as a function of composition). This defines the range of solid solution compositions which can grow by different mechanisms. We apply this approach to the $\mathrm{Ba}^{2+}-\mathrm{Sr}^{2+}$ $\mathrm{SO}_{4}^{2-} \mathrm{H}_{2} \mathrm{O} \mathrm{SS}-\mathrm{AS}$ system, in which a difference of three orders of magnitude between the solubility products of the end members, barite $\left(\mathrm{BaSO}_{4}\right)$ and celestite $\left(\mathrm{SrSO}_{4}\right)$, makes it a very suitable system to observe variations in the growth mechanisms as a function of the composition. Supersaturation functions have been calculated using computer codes developed by Prieto et al. (1993) and the $\beta^{*}$ line has been experimentally determined by means of Atomic Force Microscopy (AFM) observations of the growing barite and celestite faces at a molecular scale. AFM observations of the crystallisation behaviour of the $(\mathrm{Ba}, \mathrm{Sr}) \mathrm{SO}_{4}$ solid solution grown on barite (001) faces (such as microtopography, nucleation density, incubation time, etc.) as well as determinations of the chemical composition by microprobe analysis, are consistent with the theoretical predictions from the supersaturation-growth mechanism diagrams. Finally, we discuss the effect of both nucleation kinetics and crystallographic relationships between the substrate and the newly formed layers on the microtopographic and compositional features of the surfaces.

\section{Theoretical background}

\subsection{Supersaturation with respect to a solid solution: the $\beta$ function}

Any supersaturation calculation requires information about equilibrium conditions. In the case of 
SS-AS systems, the equilibrium relationship between the solid and aqueous phase compositions can be described by means of the so-called "solidus" and "solutus" equations (Lippmann, 1980), which express the total solubility product, $\Sigma \Pi$, as a function of the solid and liquid composition, respectively. Solidus and solutus curves can be plotted together to construct an equilibrium phase diagram, termed a Lippmann diagram (Glynn and Reardon, 1990), in which $\Sigma \Pi$ is represented on the ordinate and the composition of the solid and the aqueous phase are represented in a double scale on the abscissa. Horizontal tie lines connect solid and aqueous compositions at equilibrium.

Fig. 1 shows the Lippmann diagram for the barite-celestite $(\mathrm{Ba}, \mathrm{Sr}) \mathrm{SO}_{4}$ solid solution. The derivation of this diagram has recently been discussed in detail by Prieto et al. (1997). The $K_{\text {barite }}$ chosen for barite at $25^{\circ} \mathrm{C}$ is $10^{-9.98}$ (Blount, 1977) and $K_{\text {celestite }}$ for celestite is $10^{-6.63}$ (Reardon and Armstrong, 1987). The solubility products of the end-members of this solid solution differ by three

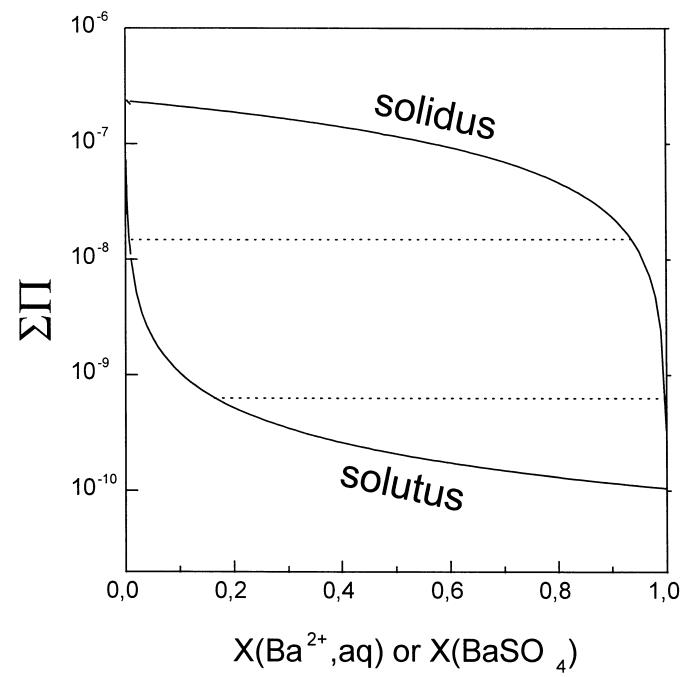

Fig. 1. Lippmann diagram for the $(\mathrm{Ba}, \mathrm{Sr}) \mathrm{SO}_{4}-\mathrm{H}_{2} \mathrm{O}$ system at $25^{\circ} \mathrm{C}$ drawn assuming an ideal solid solution. End-member solubility products chosen were $10^{-9.98}$ for barite and and $10^{-6.63}$ for celestite. The solidus and solutus curves are represented on the ordinate versus $X_{\mathrm{BaSO}_{4}}$ and $X_{\mathrm{Ba} \text {,aq }}$ on the abscissa, respectively. The tie-lines shown in the diagram connect two solid mole fractions with their corresponding aqueous activity fractions at thermodynamic equilibrium. orders of magnitude which results in the wide separation between the solutus and solidus curves and, therefore, in the extreme difference in the composition of the solid phase coexisting with the aqueous phase at equilibrium.

From the Lippmann diagram it is clear that when a SS-AS system is considered, supersaturation cannot be expressed by a unique value, but is a function of the composition of both solid and aqueous phases. The general expression for the supersaturation function, $\beta$, in a multicomponent solution which may be non-stoichiometric has the form:

$\beta=\frac{\Pi a_{i}^{\nu i}}{K_{\mathrm{s}}}$

(Prieto et al., 1994; Putnis et al., 1995) where $\Pi a_{i}^{v i}$ is the ionic activity product, $v_{i}$ is the stoichiometric number of ion, $i$, in the solute formula and $K_{\mathrm{s}}$ is the solubility product. Applying this to a solid solution of the form $B_{x} C_{1-x} A$, there are three ions $\left(\mathrm{B}^{+}, \mathrm{C}^{+}\right.$ and $\left.\mathrm{A}^{-}\right)$, three activities $\left(a\left(B^{+}\right), a\left(C^{+}\right)\right.$, and $\left.a\left(A^{-}\right)\right)$, and three stoichiometric numbers $(x, 1-x$ and 1). According to the development described by Glynn and Reardon (1990), and based on Lippmann's method, the ionic activity product can be expressed as:

$\Pi a_{i}^{\nu i}=a\left(B^{+}\right)^{x} a\left(C^{+}\right)^{(1-x)} a\left(A^{-}\right)$

However, for a binary solid solution we have two equilibrium conditions:

$a\left(B^{+}\right) a\left(A^{-}\right)=K_{B A} a_{B A}$

$a\left(C^{+}\right) a\left(A^{-}\right)=K_{C A} a_{C A}$

where $K_{B A}$ and $a_{B A}$ are the solubility product of the endmember $B A$, and the activity of the component $B A$ in the solid solution, respectively. $K_{C A}$ and $a_{C A}$ are defined in a similar way. By combining Eqs. (2), (3) and (4) and eliminating $a\left(A^{-}\right)$, one derives:

$$
\begin{aligned}
K_{\mathrm{s}} & =\left(K_{C A} a_{C A}\right)^{1-x}\left(K_{B A} a_{B A}\right)^{x} \\
& =\left(K_{C A} X_{C A} \gamma_{C A}\right)^{1-x}\left(K_{B A} X_{B A} \gamma_{B A}\right)^{x}
\end{aligned}
$$

where we express the solid phase activities as the product of mole fractions and activity coefficients in the solid phase. Therefore, from (Eqs. (1), (2) and 
(5) we can derive the general supersaturation expression:

$$
\beta=\frac{a\left(B^{+}\right)^{x} a\left(C^{+}\right)^{1-x} a\left(A^{-}\right)}{\left(K_{C A} X_{C A} \gamma_{C A}\right)^{1-x}\left(K_{B A} X_{B A} \gamma_{B A}\right)^{x}}
$$

where obviously $x=X_{B A}$ and $1-x=X_{C A}$. In order to evaluate the supersaturation by using Eq. (6), knowledge of the activities of the free ions $A^{-}, B^{+}$ and $C^{+}$in the aqueous phase and the activities of the components $B A$ and $C A$ in the solid phase are required. The activities $a\left(B^{+}\right), a\left(C^{+}\right)$, and $a\left(A^{-}\right)$, can be calculated by means of a speciation program based on the Debye-Hückel equation (Prieto et al., 1993). The activity coefficients, $\gamma_{C A}$ and $\gamma_{B A}$ of the solid solution, if known, can be found in the literature. Once all the activities in both the solid and aqueous phases are known we can calculate the supersaturation for any value $x$ from 0 to 1 and obtain the supersaturation function $\beta$.

The supersaturation function $\beta$ has been calculated for an aqueous solution with $\left[\mathrm{Ba}^{2+}\right]=1$ $\mu \mathrm{M} ;\left[\mathrm{Sr}^{2+}\right]=\left[\mathrm{SO}_{4}^{2-}\right]=2000 \mu \mathrm{M}$ (square brackets denote concentrations and the solid solution is assumed ideal) and plotted as Fig. 2. Note that, even though the aqueous solution is very Sr-rich, the maximum supersaturation corresponds to an intermediate composition of the solid. The shifting of the supersaturation value becomes specially important when the solubility of the solid solution end members are very different. In such a case, small varia-

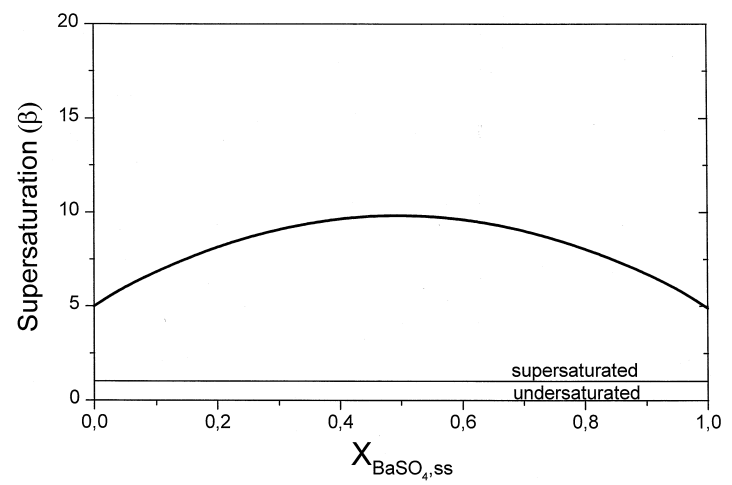

Fig. 2. Supersaturation $(\beta)$ of an aqueous solution composition with $\left[\mathrm{Ba}^{2+}\right]=1 \mu \mathrm{mol} / 1 ;\left[\mathrm{Sr}^{2+}\right]=\left[\mathrm{SO}_{4}^{2-}\right]=2000 \mu \mathrm{mol} / 1$ as a function of the solid composition $\mathrm{X}_{\mathrm{BaSO}_{4}, \mathrm{ss}}$. The $(\mathrm{Ba}, \mathrm{Sr}) \mathrm{SO}_{4}$ solid solution was assumed to be ideal (activity coefficients $=1$ ).

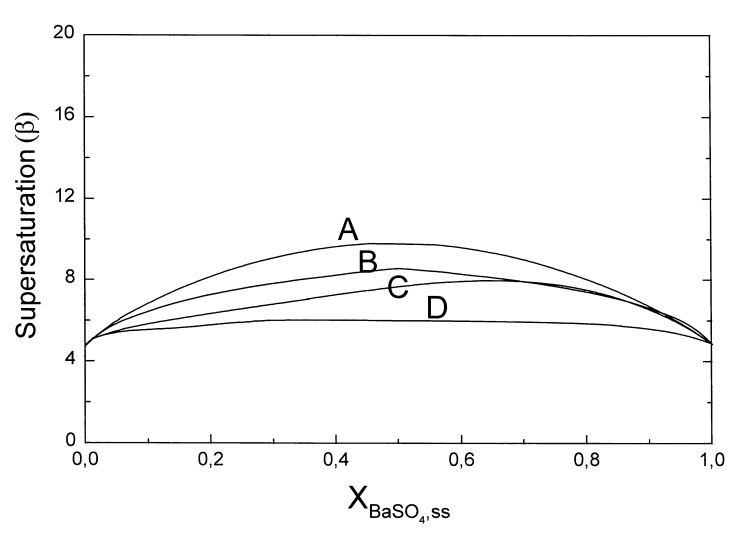

Fig. 3. Effect of non-ideality on the supersaturation curves for the system $(\mathrm{Ba}, \mathrm{Sr}) \mathrm{SO}_{4}-\mathrm{H}_{2} \mathrm{O}$. The supersaturation functions have been calculated for three cases for an aqueous solution with composition $\left[\mathrm{Ba}^{2+}\right]=1 \mu \mathrm{mol} / 1,\left[\mathrm{Sr}^{2+}\right]=\left[\mathrm{SO}_{4}^{2-}\right]=2000 \mu \mathrm{mol} / 1$. Curve A corresponds to an ideal solid solution behaviour. Curve B was obtained using a solid solution model based on empirical potentials (Becker et al., 1999). Curves C and D were calculated using a solid solution model with Redlich-Kister coefficients $a_{0}=a_{1}=1$ and $a_{0}=2$, respectively (Redlich and Kister, 1948). Non-ideality correspond to a decrease in supersaturation for the intermediate solid.

tions in the concentration of the less soluble endmember result in large changes in supersaturation distributions. It is possible for example, for an aqueous solution to show simultaneously supersaturated and undersaturated stages for different solid compositions.

The degree of ideality of the solid solution can also affect the shape of the supersaturation curves. For the case of the $(\mathrm{Ba}, \mathrm{Sr}) \mathrm{SO}_{4}$ solid solution, there are arguments in the literature for and against ideal behaviour (Hanor, 1968; Brower and Renault, 1971; Malinin and Urusov, 1983; Becker et al., 1999). When different degrees of non-ideality for the $(\mathrm{Ba}, \mathrm{Sr}) \mathrm{SO}_{4}$ solid solution are considered, the shape of the calculated supersaturation curves changes. Fig. 3 shows the supersaturation functions for a given aqueous solution when ideal (curve $\mathrm{A}$ ) and non-ideal (curves $\mathrm{B}$ to $\mathrm{D}$ ) behaviour of the $(\mathrm{Ba}, \mathrm{Sr}) \mathrm{SO}_{4}$ solid solution is assumed. The non-ideality is reflected in a decrease of the supersaturation with respect to the intermediate compositions of the solid solution. Furthermore, the supersaturation maxima are slightly shifted when non-ideality is introduced. Both effects have some influence on nucleation kinetics (e.g. 
nucleation density and incubation times) and on the composition of the two-dimensional nuclei. However, for the crystallisation of sparingly soluble solid solutions whose end members have solubility products that differ by some orders of magnitude, and when crystallisation occurs at moderate supersaturations, small deviation from ideality, as might be expected in this system, are not very significant. In effect, crystallisation behaviour is essentially controlled by the variation of solubility between pure end members.

\subsection{Growth mechanisms}

Crystals can grow according to three basic growth mechanisms: spiral growth, two-dimensional nucleation and continuous growth. The spiral growth mechanism and two-dimensional nucleation mechanisms operate under low and moderate supersaturation levels respectively. Both mechanisms exhibit specific growth kinetics and result in smooth crystal surfaces. In the case of spiral growth, the growth rate $R$, is a parabolic function of supersaturation, $\beta$, $\left(R \propto \beta^{2}\right)$, while for the two-dimensional growth mechanism an exponential dependence on supersaturation, $R \propto \beta^{v}$, is observed. At higher supersaturations, crystal surfaces become rough and growth takes place continuously so that $R \propto \beta$. Transitional supersaturations $\beta^{*}$ and $\beta^{* *}$ separate the three growth regimes (Sunagawa, 1984). Actual transitional supersaturation values vary from one substance to another and also depend on both the crystallography of the surfaces and growth conditions (temperature, viscosity, type of solvent, etc). When growth occurs under given growth conditions, crystal solubility controls the kinetics of incorporation of growth units on growing surfaces and, therefore, it strongly determines the supersaturation values at which transitions between growth mechanisms occur (Simon and Boistelle, 1981). Thus, sparingly soluble substances have higher values of $\beta^{*}$ and $\beta^{* *}$ than compounds with high solubility. If we consider the crystallisation of a solid solution, it is again necessary to take into account that the solubility is a function of the solid composition. Therefore, in contrast to pure phases with fixed composition, $\beta^{*}$ and $\beta^{* *}$ are also composition-dependent. Assuming that transitional supersaturation values depend only on

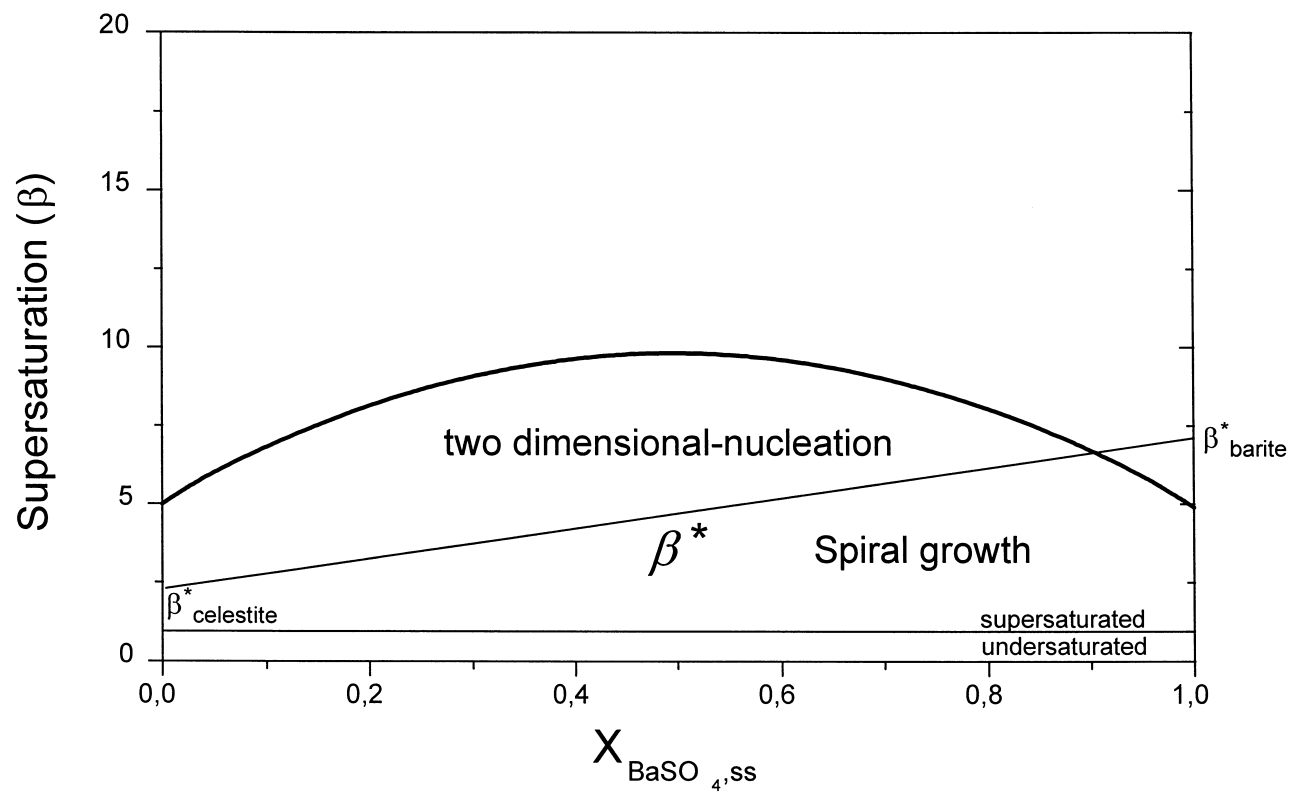

Fig. 4. Relationship between supersaturation function, $\beta\left(X_{\mathrm{BaSO}_{4}}\right)$, and growth mechanisms. The supersaturation curve corresponds to an aqueous solution composition with $\left[\mathrm{Ba}^{2+}\right]=1 \mu \mathrm{mol} / 1 ;\left[\mathrm{SO}_{4}^{2-}\right]=\left[\mathrm{Sr}^{2+}\right]=2000 \mu \mathrm{mol} / 1 . \beta_{\text {cel }}^{*}$ and $\beta_{\text {bar }}^{*}$ are the transitional supersaturation levels for celestite and barite, respectively. 
the solubility, we can also assume that $\beta^{*}$ and $\beta^{* *}$ vary linearly as a function of the solid composition between the transitional supersaturation values for the end members.

\subsection{Relationship between supersaturation and growth mechanisms}

Fig. 4 illustrates how the dominant growth mechanisms (spiral growth and two-dimensional nucleation) depend on both the supersaturation and the composition of the solid solution. The determination of the $\beta^{*}$ values for the two end members will be discussed below, and the figure is presented for illustrative purposes at this stage. The $\beta_{\text {celestite }}{ }^{*} \beta_{\text {barite }}{ }^{*}$ line separates the regions where spiral growth and two-dimensional nucleation predominates.

Fig. 4 shows that the aqueous solution is supersaturated with respect to the entire range of composition of the $(\mathrm{Ba}, \mathrm{Sr}) \mathrm{SO}_{4}$ solid solution. Below the $\beta_{\text {celestite }}^{*}-\beta_{\text {barite }}^{*}$ line the solid solution can only grow by the spiral growth mechanism whereas above such a line two-dimensional nucleation mechanism is also possible. For a given starting composition of an aqueous solution, different solid compositions can grow by different growth mechanisms.

The modification in the shapes of the supersaturation curves when the effect of non-ideality is considered leads to slight changes in the range of compositions for which spiral growth or two-dimensional nucleation operate as dominant mechanisms. However, this does not strongly change the composition-growth mechanism relationship and is insignificant at moderate to high supersaturation levels. Therefore, the diagrams shown hereafter have been constructed for an ideal $(\mathrm{Ba}, \mathrm{Sr}) \mathrm{SO}_{4}$ solid solution

\section{Experimental procedure}

\subsection{AFM crystallisation experiments}

The primary aim of the experiments was to verify the theoretical treatment of SS-AS systems outlined above by in situ observations of growth mechanisms as a function of supersaturation of the aqueous phase. A Digital Instruments Nanoscope III Multimode
AFM with a commercially available fluid cell and working in contact mode was used to study two-dimensional nucleation from a range of aqueous solution compositions in the system $\mathrm{Ba}^{2+}-\mathrm{Sr}^{2+}-\mathrm{SO}_{4}^{2-}$ $\mathrm{H}_{2} \mathrm{O}$.

The substrates used were natural barite and celestite crystals from the Mineralogical Museum of Münster and freshly cleaved on (001) at atmospheric conditions before each experiment. $\mathrm{Ba}^{2+}-\mathrm{Sr}^{2+}$ $\mathrm{SO}_{4}^{2-}-\mathrm{H}_{2} \mathrm{O}$ solutions were prepared using $\mathrm{Na}_{2} \mathrm{SO}_{4}$ and $\mathrm{BaCl}_{2}, \mathrm{Ba}\left(\mathrm{NO}_{3}\right)_{2}$ and $\mathrm{Sr}\left(\mathrm{NO}_{3}\right)_{2}$ (Sigma $99 \%$ + ). Nucleation experiments were carried out at $25^{\circ} \mathrm{C}$ using flowing solutions.

The supersaturation function for each $\mathrm{Ba}^{2+}-$ $\mathrm{Sr}^{2+}-\mathrm{SO}_{4}^{2-}-\mathrm{H}_{2} \mathrm{O}$ solution was calculated using a speciation program (Prieto et al., 1993). This program initially calculates the activities for chemical species (charged species: $\mathrm{Ba}^{2+}, \mathrm{Sr}^{2+}, \mathrm{Na}^{+}, \mathrm{H}^{+}$, $\mathrm{BaOH}^{+}, \mathrm{SrOH}^{+}, \mathrm{SO}_{4}^{2-}, \mathrm{Cl}^{-}, \mathrm{OH}^{-}, \mathrm{HSO}_{4}^{-}, \mathrm{NaSO}_{4}^{-}$; uncharged species: $\mathrm{BaSO}_{4}^{\circ}, \mathrm{SrSO}_{4}^{\circ}$ ). Once the activities are known, the supersaturation function is computed using Eq. (6) applied for the particular case of the $\mathrm{Ba}^{2+}-\mathrm{Sr}^{2+}-\mathrm{SO}_{4}^{2-}-\mathrm{H}_{2} \mathrm{O}$ system and for the entire compositional range from $x=0$ to $x=1$ :

$\beta=\frac{a\left(\mathrm{Ba}^{2+}\right)^{x} a\left(\mathrm{Sr}^{2+}\right)^{1-x} a\left(\mathrm{SO}_{4}^{2-}\right)}{\left(K_{\mathrm{BaSO}_{4}} X_{\mathrm{BaSO}_{4}} \gamma_{\mathrm{BaSO}_{4}}\right)^{x}\left(K_{\mathrm{SrSO}_{4}} X_{\mathrm{SrSO}_{4}} \gamma_{\mathrm{SrSO}_{4}}\right)^{1-x}}$

where $a\left(\mathrm{Ba}^{2+}\right), a\left(\mathrm{Sr}^{2+}\right)$ and $a\left(\mathrm{SO}_{4}^{2-}\right)$ represent the activities of the free ions in solution; $K_{\mathrm{BaSO}_{4}}$ and $K_{\mathrm{SrSO}_{4}}$, the solubility product of the endmembers barite and celestite; $X_{\mathrm{BaSO}_{4}}$ and $X_{\mathrm{SrSO}_{4}}$, the molar fraction of $\mathrm{BaSO}_{4}$ and $\mathrm{SrSO}_{4}$ in the solid and $\gamma_{\mathrm{BaSO}_{4}}$ and $\gamma_{\mathrm{SrSO}_{4}}$, the corresponding activity coefficients. For all calculations, the solid solution $(\mathrm{Ba}, \mathrm{Sr}) \mathrm{SO}_{4}$ was assumed to be ideal (activity coefficients equal to 1$)$.

The initial experiments determined transitional supersaturation values, $\beta^{*}$, for the onset of two-dimensional nucleation for both celestite and barite end members of the solid solution. The nucleation experiments were carried out in situ by flowing the aqueous solutions over (001) cleavage surfaces of celestite and barite, and growth was observed by $\mathrm{AFM}$ as a function of increasing supersaturation. The aqueous solutions used in these cases contained only the relevant end member components. Growth mechanisms were then studied using non-stoichiometric 
aqueous solutions containing $\mathrm{Ba}^{2+}, \mathrm{Sr}^{2+}$ and $\mathrm{SO}_{4}^{2-}$ in contact with pure barite (001) substrates. Observations were made of the microtopography of the surfaces during growth and nucleation density (in nuclei $/ \mu \mathrm{m}^{2}$ ) and incubation times (i.e. the time elapsed between injection of the solution and observation of the first nuclei on the surface) were determined.

\subsection{Electron microprobe chemical analysis of the surfaces}

Samples in which the aqueous solutions were passed over the barite substrate for sufficient time to allow greater thickness (200 to $800 \mathrm{~nm}$ ) of overgrowth to be formed were studied by scanning electron microscopy and electron microprobe microanalysis (using a JEOL $8600 \mathrm{MXA}$ at $10 \mathrm{kV}$ and a JEOL 6300F SEM). In both instruments, the acceleration voltage was set to a minimum to decrease the influence of the barite substrate (with high average atomic number) during imaging. During microanalysis three problems were encountered: (i) First, thinness of newly formed layers required a minimum excitation voltage to restrict the generation of X-rays to the layer under examination; (ii) imaging the newly formed growth steps needed a minimum beam diameter to achieve a optimum spatial resolution; and (iii) a sufficient number of total counts was needed to ensure minimum analytical errors.

The depth of X-ray generation in this system can be evaluated by first considering the electron penetration when a layer of pure $\mathrm{SrSO}_{4}$ overlies a barite substrate. The maximum depth of penetration through pure $\mathrm{SrSO}_{4}$ before generation of $\mathrm{BaL}_{\alpha} \mathrm{X}$-rays from the substrate was calculated using Kanaya-Okayama electron penetration ranges and limiting the maximum electron range with the critical excitation energy of $\mathrm{Ba}, \mathrm{Sr}$ and $\mathrm{S} \mathrm{X}$-ray lines (Goldstein et al., 1992). Assuming an ideal $\mathrm{SrSO}_{4}$ overlayer with a density of $3.96 \mathrm{~g} / \mathrm{cm}^{3}$, the maximum penetration depth before $\mathrm{BaL}_{\alpha} \mathrm{X}$-ray generation was calculated to be $620 \mathrm{~nm}$. The presence of $(\mathrm{Ba}, \mathrm{Sr}) \mathrm{SO}_{4}$ solid solution in the overlayer would significantly reduce this penetration depth. Thus analyses of overlayers containing (Ba,Sr)SO $\mathrm{SO}_{4}$ with thickness near $620 \mathrm{~nm}$ are not likely to be contaminated by the substrate.
All analyses of the surface layers were Sr-rich but had totals of about $95 \mathrm{wt} . \%$ and less. The remeasurement of the $\mathrm{SrSO}_{4}$ standards resulted in 100 wt.\% analysis with ideal stochiometry. This confirmed a reliable standardisation procedure. The deviation of the totals of the analysis can be attributed to a number of possible factors including (i) a submicron porosity within the newly formed surface layer, (ii) a non-flat crystallised surface layer influencing the focus of the WD-spectrometers or (iii) the occurrence of light elements, not detected by the microprobe, within the newly formed layer. The possibility of porosity or the contribution of light elements was included in a second calculation assuming a density decrease of $5 \%$ of the newly formed layer. This assumption only slightly affects the calculated maximum penetration depth.

\section{Results}

\subsection{Determination of the transitional supersatura- tion between spiral growth and two-dimensional nu- cleation mechanisms}

The transitional supersaturation for two dimensional nucleation was determined for each end member composition by in situ AFM growth experiments in the fluid cell. By increasing the supersaturation of pure end member solutions passing over (001) barite and celestite substrates, the transitional supersaturation is found to be the point at which two dimensional nuclei are observed for the first time. The transition from spiral growth to two-dimensional nucleation of pure $\mathrm{BaSO}_{4}$ on barite (001) occurs approximately when $\beta_{\text {barite }}^{*}=7.0$ (this work). In the case of celestite, $\beta_{\text {celestite }}^{*}=2.3$ (calculated from data collected by Risthaus, personal communication). The transitional supersaturation values are, in principle, very sensitive to growth conditions and crystallography of growing faces. The values reported here were determined under the same conditions of temperature, flow rate, surface topography, etc.

\subsection{Crystallisation behaviour of the $(\mathrm{Ba}, \mathrm{Sr}) \mathrm{SO}_{4}$ solid solution}

To study the crystallisation behaviour of the $(\mathrm{Ba}, \mathrm{Sr}) \mathrm{SO}_{4}$ solid solution, a number of aqueous solu- 


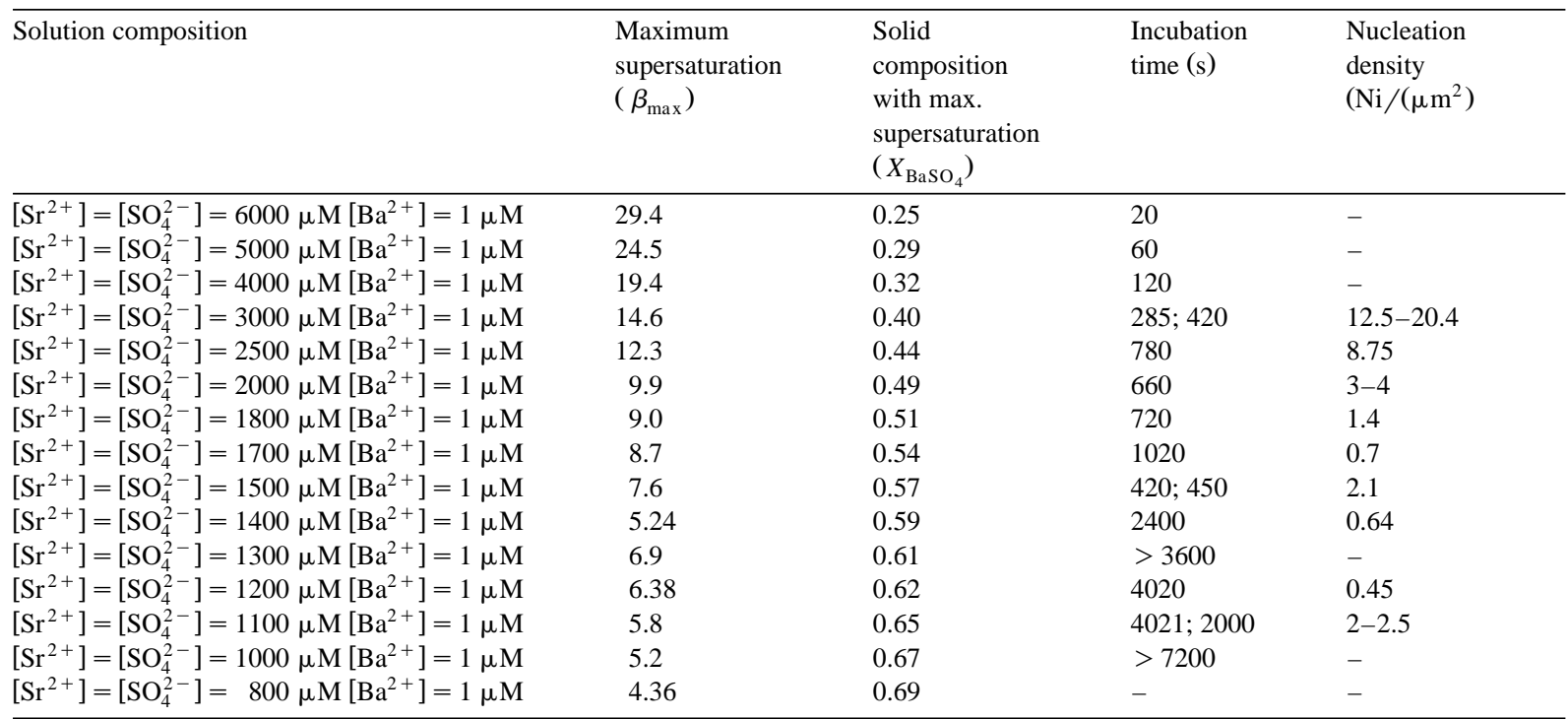

tions with different ratios of $\mathrm{Ba}^{2+}, \mathrm{Sr}^{2+}$ and $\mathrm{SO}_{4}^{2-}$ were passed over barite (001) cleavage surfaces in the fluid cell of the AFM. In addition to the qualitative observations (morphological features and the distribution of nuclei on the surfaces) which provided general information about the development of the crystallisation process, nucleation parameters (such as nucleation density and incubation time) were also obtained from the experiments. In Table 1, the initial conditions for the experiments, such as composition of the solutions, maximum supersaturation, etc., and nucleation data are reported.

Fig. 5 shows three representative crystallisation experiments for which two-dimensional nucleation was observed over a wide range of solid composition. Two-dimensional nuclei developed on barite (001) faces from solutions with decreasing supersaturation (Fig. 5a-f). In each case, the maxi- mum supersaturation corresponded to intermediate ( $\mathrm{Ba}, \mathrm{Sr}) \mathrm{SO}_{4}$ solid solution compositions, but as we will show in Section 4.3 and discuss later, the composition of the layers formed by two-dimensional nucleation does not necessarily correspond to the maximum supersaturation and is very Sr-rich in all cases. The plots at the left side of Fig. 5 show the supersaturation functions calculated for the aqueous solutions used and the expected compositional ranges for which spiral growth or two-dimensional nucleation are dominant (regions defined by intersection between the supersaturation curve and $\beta^{*}$ line). The AFM images at the right side of Fig. 5 were taken a few minutes after nucleation occurred.

Fig. 5a shows the supersaturation distribution for an aqueous solution with composition $\left[\mathrm{Ba}^{2+}\right]=1$ $\mu \mathrm{mol} / 1,\left[\mathrm{Sr}^{2+}\right]=\left[\mathrm{SO}_{4}^{2-}\right]=3000 \mu \mathrm{mol} / 1$. This solution is supersaturated with respect to all composi-

Fig. 5. Supersaturation-solid composition diagrams and AFM images of the barite (001) face during growth. The images were taken in constant force mode while displaying the cantilever deflection signal. The scan area is $15 \times 15 \mu \mathrm{m}^{2}$ in the three cases. (a) Solution: $\left[\mathrm{Ba}^{2+}\right]=1 \mu \mathrm{mol} / 1,\left[\mathrm{Sr}^{2+}\right]=\left[\mathrm{SO}_{4}^{2-}\right]=3000 \mu \mathrm{mol} / \mathrm{l}$. (b) When such a solution is passed over the barite surface, two-dimensional nucleation with high nucleation density is developed. Nuclei preferentially grow on step edges. (c) Solution $\left[\mathrm{Ba}^{2+}\right]=1 \mu \mathrm{mol} / 1$, $\left[\mathrm{Sr}^{2+}\right]=\left[\mathrm{SO}_{4}^{2-}\right]=2000 \mu \mathrm{mol} / 1$. (d) Two-dimensional nuclei formed on the barite surface, again located along cleavage steps. (e) Solution $[\mathrm{Ba}]=1 \mu \mathrm{mol} / 1,[\mathrm{Sr}]=1100 \mu \mathrm{mol} / 1$ and $\left[\mathrm{SO}_{4}\right]=1100 \mu \mathrm{mol} / 1$. (f) Two-dimensional islands are oriented with respect to the initial cleavage steps and exhibit ellipsoidal shapes. In this image, cleavage steps advance can be also observed (black arrows). 
tions of the $(\mathrm{Ba}, \mathrm{Sr}) \mathrm{SO}_{4}$ solid solution, with the maximum supersaturation value $(\beta=15)$ corresponding to a solid composition $X_{\mathrm{BaSO}_{4}}=0.40$. The relationship between the supersaturation curve and the transitional $\beta^{*}$ line indicates that two-dimensional nucleation is possible for all compositions of
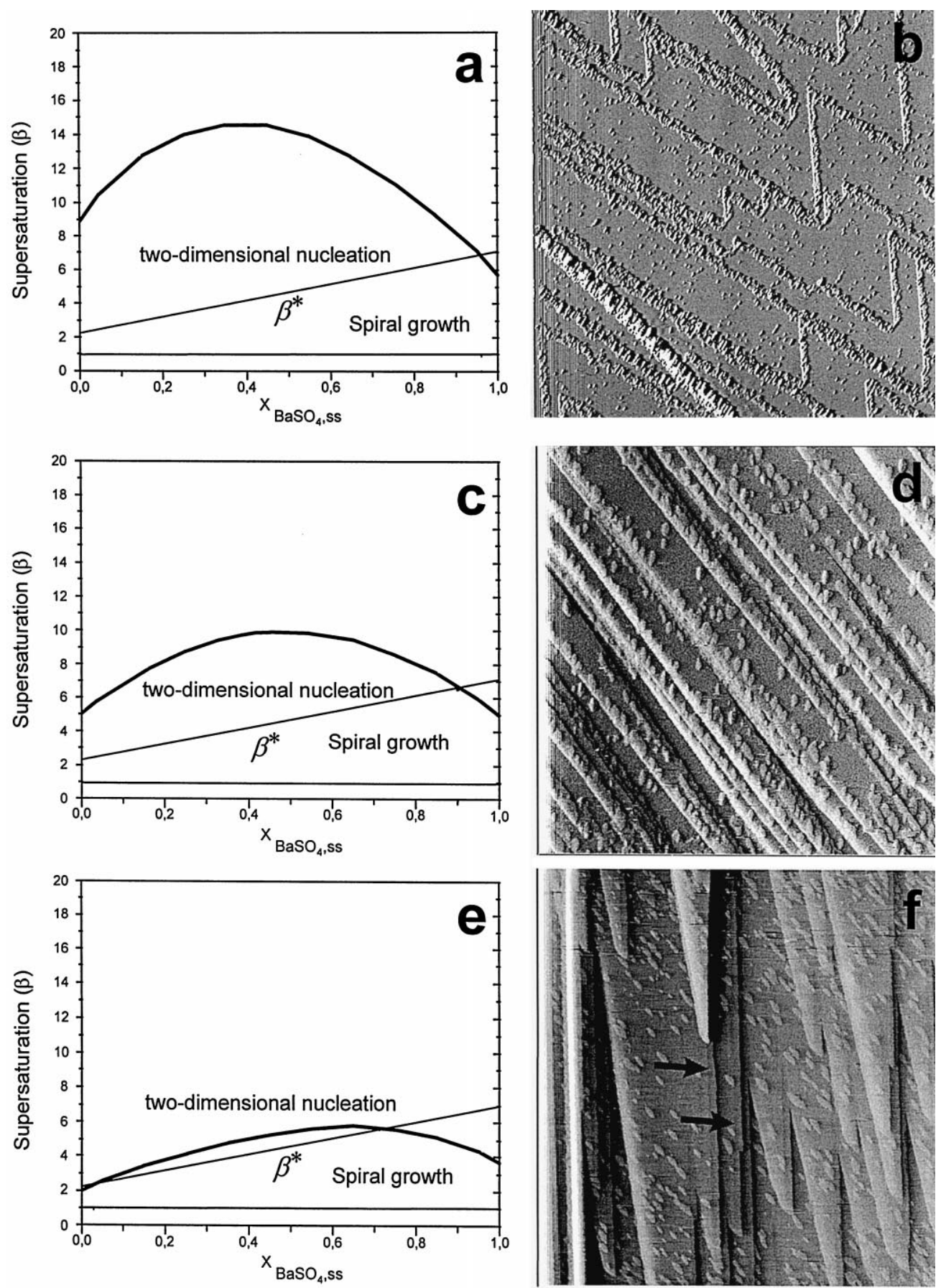
the solid solution with molar fractions $X_{\mathrm{BaSO}_{4}}<0.96$. When this solution was passed over a barite (001) surface, two-dimensional nucleation occurred after an incubation time of around $350 \mathrm{~s}$ (Fig. 5b). Precipitation is characterised by a high nucleation density (12 to 20 nuclei $/ \mu \mathrm{m}^{2}$ ) and by the development of two-dimensional (i.e. one molecular layer thick) islands 3.6 ̊̊ high, with ellipsoidal morphologies (Fig. $5 b)$. The islands appear to be distributed over the whole surface, but preferentially on the cleavage step edges.

When a solution with composition $\left[\mathrm{Ba}^{2+}\right]=1$ $\mu \mathrm{mol} / 1,\left[\mathrm{Sr}^{2+}\right]=\left[\mathrm{SO}_{4}^{2-}\right]=2000 \mu \mathrm{mol} / 1$ is used, the supersaturation levels are decreased (Fig. 5c), but two-dimensional nucleation is again possible for most of the compositions of the $(\mathrm{Ba}, \mathrm{Sr}) \mathrm{SO}_{4}$ solid solution $\left(X_{\mathrm{BaSO}_{4}}<0.91\right)$. The maximum supersaturation is now $\beta=9.5$ and relates to a solid composition with molar fraction $X_{\mathrm{BaSO}_{4}}=0.49$, and this has an obvious effect on the nucleation parameters. The nucleation density decreases ( 3 to 4 nuclei $/ \mu \mathrm{m}^{2}$ ) and the incubation time increases (660 s) (Fig. 5d). Again, nucleation does not occur homogeneously on the initial barite substrate, but nuclei are distributed preferentially along the step edges.

Finally, Fig. 5e shows the diagram corresponding to a solution with $\left[\mathrm{Ba}^{2+}\right]=1 \mu \mathrm{mol} / 1,\left[\mathrm{Sr}^{2+}\right]=$ $\left[\mathrm{SO}_{4}^{2-}\right]=1100 \mu \mathrm{mol} / 1$. The maximum supersaturation $(\beta=6.0)$ occurs for the solid composition $X_{\mathrm{BaSO}_{4}}=0.65$, and the supersaturation curve lies only just above the $\beta_{\text {celestite }}^{*}-\beta_{\text {barite }}^{*}$ line. In this case, two-dimensional nucleation can only occur for solid compositions with molar fractions $0.03<X_{\mathrm{BaSO}_{4}}<$ 0.71 . Nucleation on a barite surface in contact with this solution was detected only after a long incubation time (4021 s) (Fig. 5f). The nucleation density is, however, quite similar to that observed in the previous case ( 2 to 2.5 nuclei $/ \mu \mathrm{m}^{2}$ ). These islands again form preferentially on the initial cleavage steps. In this image the advance of these initial cleavage steps can also be observed (Fig. 5f).

The two-dimensional islands shown in Fig. 5 are formed by few growth layers and the ellipsoidal shape remains during the observation time. However, when more highly supersaturated solutions are used many growth layers are formed in a short time and the islands rapidly grow perpendicularly to the barite (001) surface. As growth proceeds the initial ellip- soidal shape of the islands changes and becomes polygonal. Fig. 6a shows a number of $(\mathrm{Ba}, \mathrm{Sr}) \mathrm{SO}_{4}$ polygonal islands deposited a few seconds after injecting a solution with concentration $\left[\mathrm{Ba}^{2+}\right]=1$ $\mu \mathrm{mol} / 1,\left[\mathrm{Sr}^{2+}\right]=\left[\mathrm{SO}_{4}^{2-}\right]=5000 \mu \mathrm{mol} / \mathrm{l} \quad(\beta=$ $24.5)$. Islands nucleate on the surface and on cleavage steps in the same orientation as the step edges. Further development of the two-dimensional islands deposited on steps leads to their coalescence and to the formation of $(\mathrm{Ba}, \mathrm{Sr}) \mathrm{SO}_{4}$ rims several hundred

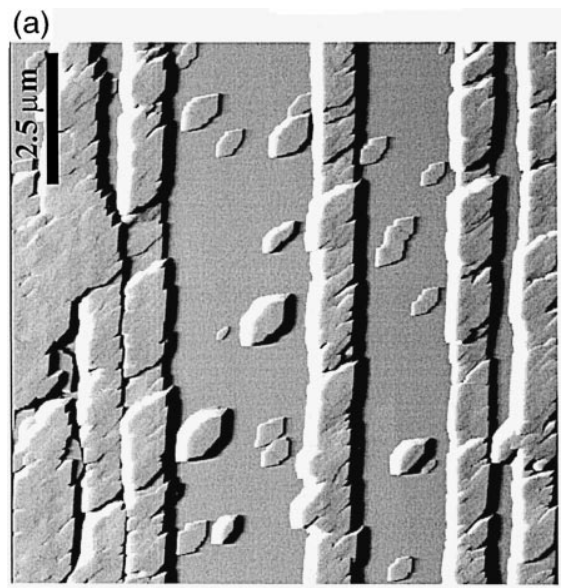

(b)

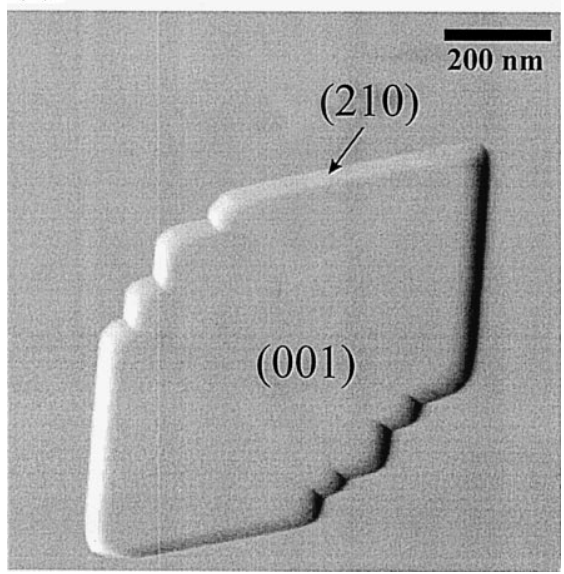

Fig. 6. (a) Nucleation of $(\mathrm{Ba}, \mathrm{Sr}) \mathrm{SO}_{4}$ on barite (001) surface from a solution of $\left[\mathrm{Ba}^{2+}\right]=1 \mu \mathrm{mol} / 1, \quad\left[\mathrm{Sr}^{2+}\right]=\left[\mathrm{SO}_{4}^{2-}\right]=5000$ $\mu \mathrm{mol} / \mathrm{l}$. (b) Detail of a single two-dimensional island showing a typical polyhedral morphology defined by (001) and $\{210\}$ forms. Both AFM images were taken in constant force mode while displaying the cantilever deflection signal. The height of the islands, a few seconds after nucleation, ranges from 20 to $160 \mathrm{~nm}$ (i.e, from 30 to 230 celestite unit cells). 
nanometres wide. After some minutes of growth, the thickness of both single islands and rims ranges from few tens of unit cells to several hundreds. In contrast, the spreading on the initial barite surface is slower. Goniometric measurements of the islands showed that their polygonal shape is basically defined by the (001) and $\{210\}$ forms (Fig. 6b). The $\{100\}$ form is only present in later stages of growth and when the thickness of the islands is high.

For dilute $\mathrm{Ba}^{2+}-\mathrm{Sr}^{2+}-\mathrm{SO}_{4}^{2-}$ solutions, whose supersaturation curve lies below the $\beta^{*}$ line, two-dimensional nucleation is theoretically not possible and the only viable growth mechanism is the advance of cleavage steps and spiral growth. The existence of such a transitional supersaturation line is reflected in the increase of the incubation time for progressively less concentrated solutions. Fig. 7 shows the relationship between supersaturation and incubation time. The incubation time was measured for a range of solution compositions with decreasing supersaturation relative to the $(\mathrm{Ba}, \mathrm{Sr}) \mathrm{SO}_{4}$ solid solution. As the supersaturation is decreased, the incubation time exponentially increases. The exponential dependence of the incubation time on the maximum supersaturation (which corresponds in all cases to intermediate compositions and constitutes an indica- tor of the decrease of the supersaturation values for the complete solid solution) shows that for supersaturation curves with maximum below $\beta \approx 6$, i.e., solutions with sulphate and strontium concentrations below $1000 \mu \mathrm{M}$ (and with $\left[\mathrm{Ba}^{2+}\right]=1 \mu \mathrm{M}$ ), the incubation times goes to infinity.

\subsection{Composition of the surfaces after growth}

Electron microprobe microanalysis and scanning electron microscopy were carried out on three samples in which solutions with compositions the same as those in Fig. 5 were made to flow over a (001) barite substrate for several hours. At the lowest $\mathrm{Sr}$ concentration (corresponding to Fig. 5e), scanning electron microscopy showed overgrowths along cleavage steps on the barite substrate. Backscattered electron images confirm that the overgrowths had a lower average atomic number than the substrate and hence were Sr-rich, but the small size of the overgrowths precluded fully quantitative analysis. Analysis of the substrate indicated $\sim 1 \%$ Sr p.f.u. (per formula unit) in the precipitate which may result from a very thin Sr-enriched surface layer. With increased $\mathrm{Sr}$ content in the aqueous solution (corresponding to Fig. 5c) more obvious Sr-rich over-

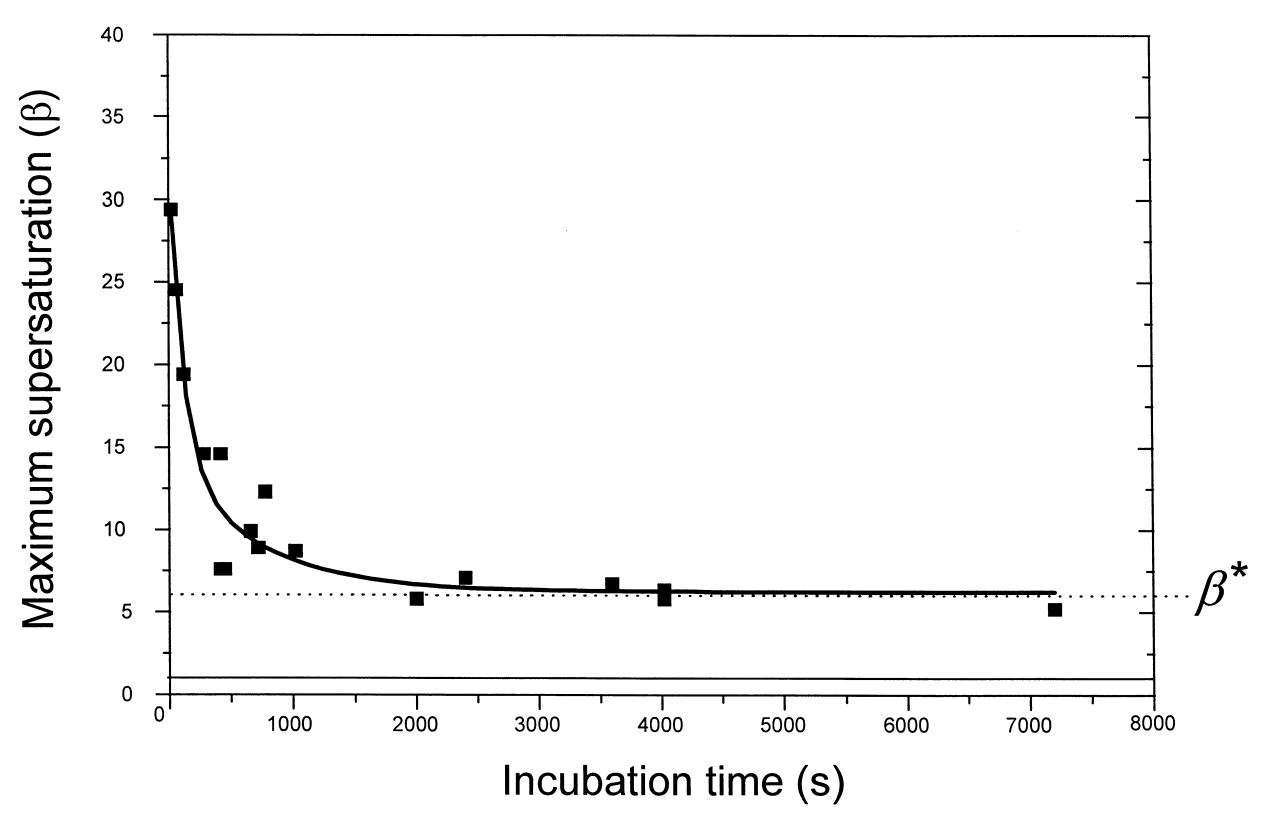

Fig. 7. Maximum supersaturation versus incubation time for two-dimensional nucleation. Data from Table 1. 
growths could be seen on the surface. The rather erratic surface coverage allowed spot analyses to be made of virtually pure barite substrate and overgrowths where the $\mathrm{Sr}: \mathrm{Ba}$ ratio approached 1. The third sample, treated with the solution having the highest $\mathrm{Sr}$ content (corresponding to Fig. 5a), was almost completely covered by a Sr-rich layer of variable thickness. Spot analyses varied from over 90\% $\mathrm{Sr}$ to about $50 \% \mathrm{SrSO}_{4}$, but the uneven coverage made quantitative analysis unreliable. The microprobe results merely confirmed that the overgrowths were Sr-rich, composed of at least $90 \%$ (or possibly pure) $\mathrm{SrSO}_{4}$.

\section{Discussion}

\subsection{Transitional supersaturation values for the ( $\mathrm{Ba}, \mathrm{Sr}) \mathrm{SO}_{4}$ solid solution}

The transitional supersaturations, $\beta^{*}=7.0$ for barite and $\beta^{*}=2.3$ for celestite, represent the supersaturation values above which two-dimensional nucleation begins. Due to the strong anisotropy of layer growth on (001) of barite and celestite, the spiral growth mechanism is strongly structurally self-inhibited (i.e., spiral growth contributes very little to the growth rate) (Pina et al., 1998a,b; Risthaus et al., 1998) and therefore these supersaturation values can be considered as effective transitional values between spiral growth and two-dimensional nucleation mechanisms. The difference observed in the values at which this transition occurs for barite and for celestite is related to physicochemical properties of the ionic crystals, such as solvation of the constituent ions, dissolution enthalpy, interfacial free energy, etc. These factors are also related to solubility and exert a direct influence on nucleation kinetics. The solubility products for these substances reported in the literature are $K_{\text {barite }}=10^{-9.98}$ (Reardon and Armstrong, 1987) and $K_{\text {celestite }}=10^{-6.63}$ (Blount,1977), and the interfacial tensions obtained from homogeneous nucleation experiments are 135$137 \mathrm{~mJ} / \mathrm{cm}^{2}$ for barite and $85-92 \mathrm{~mJ} / \mathrm{cm}^{2}$ for celestite (Nielsen and Sohnel, 1971; Söhnel, 1982). Generally, the higher the solubility, the lower the interfacial free energy, and the lower the transitional supersaturation value at which homogeneous and heteogeneous nucleation begins. The higher transitional supersaturation for barite (less soluble) than for celestite is clearly in agreement with such a rule.

In Section 4.1, a linear variation, as a function of the solid solution composition, of the transitional supersaturation between $\beta_{\text {barite }}^{*}$ and $\beta_{\text {celestite }}$ was assumed in order to relate supersaturation states of the aqueous solution to the observed growth mechanisms, i.e., the $\beta^{*}$ line. The exponential curve shown in Fig. 7, where the incubation time goes to infinity as the maximum supersaturation decreases, indicates that such an assumption is essentially correct, demonstrating that the variation of the solubility with solid solution composition is the main factor controlling the change in growth mechanisms.

\subsection{Relationship between growth mechanisms, su- persaturation functions and surface composition}

The supersaturation-solid composition diagrams (Fig. 5) show the range of solid compositions for which two-dimensional nucleation operates as the main growth mechanism. However, from the relationships between supersaturation curves and transitional supersaturation lines, it is in principle not possible to estimate the actual composition of the two-dimensional islands formed on the barite (001) surface. Only when supersaturation curves define a very narrow range of compositions for which twodimensional nucleation is possible, could the composition of the islands be estimated within a small interval. For most cases, when two-dimensional nucleation is possible for a wide range of compositions, the situation is more complex. Microprobe analysis of the newly formed layers suggest a composition close to $\mathrm{SrSO}_{4}$ whereas in principle, we would expect that the solid composition formed to be that for which the supersaturation is a maximum.

This kind of anomalous compositional behaviour, also observed in the crystallisation of $(\mathrm{Ba}, \mathrm{Sr}) \mathrm{SO}_{4}$ solid solution in gels (Prieto et al., 1993) or in the precipitation of $(\mathrm{Sr}, \mathrm{Ca}) \mathrm{CO}_{3}$ from aqueous solution (Plummer and Busenberg, 1987), demonstrates again the limitation of the concept of supersaturation in the case of the crystallisation of solid solutions. In order to understand better the relation between aqueous solution chemistry and the solid solution composition, it is necessary to take into account the kinetics 
of the nucleation. For this purpose it is worth considering in some detail the factors which govern the nucleation process from aqueous solution. According to the classical nucleation theory the relationship between nucleation rate, $J$, and supersaturation, $S$, is given by the expression (Söhnel,1982):

$J=\Gamma \exp \left[\frac{-B \xi \sigma^{3} \Omega^{2}}{k^{3} T^{3}(\ln S)^{2}}\right]$

where $J$ represents the number of nuclei formed per unit of area, $\Omega$, the molecular volume, $k$, the Boltzmann constant, $T$, absolute temperature, $B$, a geometrical factor which depends on the shape of the nuclei $(2 \pi / 3$ for a spherical nucleus and 32 for a cubic one), $\zeta$, a correction factor $(0<\xi<1)$ related to the formation of heterogeneous nuclei, $S$, the supersaturation $(S=\sqrt{ } \beta)$ and $\sigma$, the interfacial free energy. Finally, $\Gamma$ is a pre-exponential factor which involves a volume diffusion step and is dependent on solubility and interfacial tension values. Eq. (8) clearly shows that nucleation kinetics is controlled by a number of redundant parameters, among which supersaturation and surface interfacial free energy play an essential and opposite role: the nucleation rate increases when the supersaturation increases and it decreases with increasing interfacial free energy. For pure substances, and under given conditions the nucleation rate will be a single value, higher for compounds with lower interfacial free energy (high solubility) and higher also when supersaturation is higher. The situation is more complex in SS-AS systems. In such a case to evaluate the nucleation rate it is necessary to take into account that the main controlling factors in the nucleation rate equation, $S$, $\sigma, \Gamma$ and $\Omega$, are not independent parameters, but a function of the solid composition. That means that for each possible composition of the solid solution we will have a supersaturation, an interfacial free energy, and values of $\Omega$ and $\Gamma$. Therefore, Eq. (8) must be rewritten as:

$J(x)=\Gamma(x) \exp \left[\frac{-B \xi \sigma(x)^{3} \Omega(x)^{2}}{k^{3} T^{3}(\ln S(x))^{2}}\right]$

where, $S(x), \sigma(x), \Omega(x)$ and $\Gamma(x)$ are now functions of the solid composition.
As an example, Fig. 8a shows the nucleation rate function, $J(x)$, calculated for the particular aqueous solution with composition $\left[\mathrm{Ba}^{2+}\right]=1 \mu \mathrm{mol} / 1$, $\left[\mathrm{Sr}^{2+}\right]=\left[\mathrm{SO}_{4}^{2-}\right]=3000 \mu \mathrm{mol} / 1$, and whose corresponding supersaturation curve is represented in Fig. 8 b. To calculate such a nucleation rate distribution, we assumed a linear variation for the basic parameters, $\sigma(x), \Gamma(x)$ and $\Omega(x)$ from celestite to barite. The values of $\sigma$ and $\Gamma$ for these endmembers have
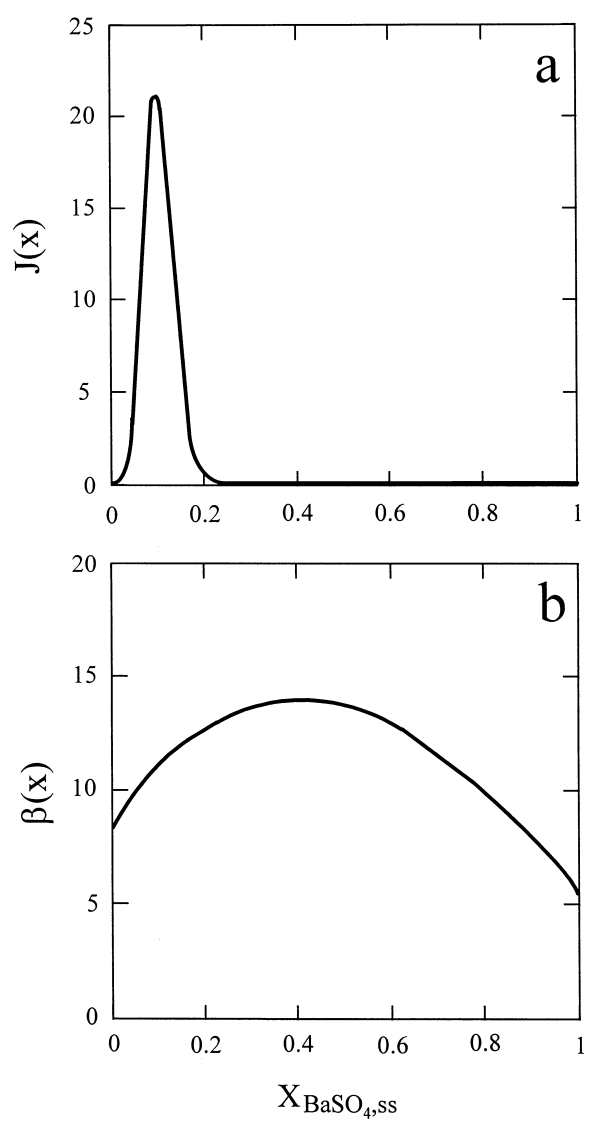

Fig. 8. (a) Nucleation rate distribution, $J(x)$, as a function of the solid composition for an aqueous solution with composition [Ba] $=1 \mu \mathrm{mol} / 1,[\mathrm{Sr}]=3000 \mu \mathrm{mol} / 1$ and $\left[\mathrm{SO}_{4}\right]=3000 \mu \mathrm{mol} / 1$. The nucleation rate is expressed in nuclei $\mu \mathrm{m}^{2} \mathrm{~s}^{-1}$. The starting nucleation parameters were taken from the literature (see text) and the correction factor for heterogeneous nucleation, $\zeta$, was adjusted considering the nucleation densities observed in the AFM experiments. (b) Supersaturation function calculated for the same aqueous solution as (a). Note that while the maximum supersaturation corresponds to a $(\mathrm{Ba}, \mathrm{Sr}) \mathrm{SO}_{4}$ solid with molar fraction $X_{\mathrm{BaSO}_{4}}=$ 0.40 , the nucleation rate maximum is located at $X_{\mathrm{BaSO}_{4}}=0.1$. 
been obtained from the literature for homogeneous nucleation. They are: $\sigma_{\text {(celestite) }}=92 \mathrm{~mJ} / \mathrm{m}^{2}$ celestite (Nielsen and Sohnel, 1971) and $\sigma_{\text {barite }}=137 \mathrm{~mJ} / \mathrm{m}^{2}$ (Söhnel, 1982); $\Gamma_{\text {barite }}=10^{28.3} \mathrm{~m}^{-3} \mathrm{~s}^{-1}$ and $\Gamma_{\text {celestite }}$ $=10^{17.8} \mathrm{~m}^{-3} \mathrm{~s}^{-1}$ (Walton, 1969). The calculated molecular volumes for celestite and barite are $\Omega_{\text {celestite }}=6.73 \cdot 10^{-29} \mathrm{~m}^{3}$ and $\Omega_{\text {barite }}=7.69 \cdot 10^{-29}$ $\mathrm{m}^{3}$, respectively.

As can be observed in Fig. 8 the maximum nucleation rate does not correspond to the solid composition for which supersaturation reaches its maximum value. Instead, the maximum nucleation rate is obtained for a Sr-rich solid $\left(X_{\mathrm{BaSO}_{4}}=0.1\right)$. This means that the formation of a Sr-rich phase (i.e., with lower surface tension and lower solubility) from this given aqueous solution is kinetically favoured. This is in agreement with the observation of $\mathrm{SrSO}_{4}$-rich layers formed on barite substrate from the aqueous solutions with composition $\left[\mathrm{Ba}^{2+}\right]=1$ $\mu \mathrm{mol} / 1,\left[\mathrm{Sr}^{2+}\right]=\left[\mathrm{SO}_{4}^{2-}\right]=3000 \mu \mathrm{mol} / 1$. Similar results have been also obtained for the rest of the solutions used in the AFM growth experiments, providing a general explanation for the compositional shift of the newly grown $(\mathrm{Ba}, \mathrm{Sr}) \mathrm{SO}_{4}$ layers towards the celestite end-member. However, it is important to mention that a precise prediction of the actual composition of the solid solution which will be formed on the barite substrate is at present not possible using nucleation rate distributions. The reason lies in the extreme sensitivity of Eq. (9) to small changes in the starting parameters, which can lead to appreciable variation in the position of the maximum for the nucleation rate, especially on the absolute nucleation rate values. Moreover, the initial parameters introduced in Eq. (9) were obtained from homogeneous nucleation experiments and it is difficult to say to what extent they can be applied to heterogeneous nucleation. Nevertheless, it is clear that the growth and chemistry of the (Ba,Sr)SO $\mathrm{SO}_{4}$ solid is mainly controlled by the relationship between the supersaturation curves and the $\beta^{*}$ line, and by the redundant nucleation kinetics of each composition.

\subsection{The influence of the substrate on the nucleation behaviour}

Another interesting aspect revealed by the AFM observations is the influence of the barite substrate on the development of $(\mathrm{Ba}, \mathrm{Sr}) \mathrm{SO}_{4}$ two-dimensional nuclei. Nuclei appear preferentially on the edges of the initial cleavage steps, demonstrating differences in the nature of nucleation sites on crystallising surfaces. Two main types of nucleation sites have been distinguished: regular (or ideal) sites and singular (or active) sites (Chernov, 1984). The latter are of different kind (steps, ledges, kinks, surface vacancies, etc.) and they are associated with a lower potential barrier. When the energy barrier is similar for all nucleation sites (ideal and active) heterogeneous nucleation occurs homogeneously on the surface. Conversely, when the energy barrier is different for different nucleation sites, nuclei will appear preferentially on the energetically more favourable ones. This phenomenon is usually called decoration and provides information about the distribution of the active sites on the surface.

Figs. 5 and 6 show the decoration of the barite (001) surface with $(\mathrm{Ba}, \mathrm{Sr}) \mathrm{SO}_{4}$ nuclei. The sites of the preferential nucleation are the cleavage steps, which display a high density of active sites with a lower energy barrier for nucleation. However, such preferential nucleation at active sites on steps is not only related to their lower energy barrier, but also to the lattice mismatch when the composition of the nuclei and the substrate differs. For pure $\mathrm{BaSO}_{4}$ solutions at similar supersaturation levels, a homogeneous distribution of nuclei on the barite (001) face is always observed (Bosbach et al., 1998; Pina et al., 1998a,b). Therefore, we can conclude that the energetically more favourable sites becomes important only when there is a mismatch between nuclei and substrate.

The barite (001) substrate not only influences the distribution of the nuclei on the surface, but also seems to exert a control on the shape and development of the two-dimensional islands. The lattice constants for pure barite are $a=8.87 \AA, b=5.45 \AA$, $c=7.15 \AA$, whereas for celestite they are $a=8.37$ $\AA, b=5.35 \AA, c=6.87 \AA$. If we consider the case of two-dimensional nucleation of pure $\mathrm{SrSO}_{4}$ on the (001) face of pure barite, the mismatch $\delta=[\mathrm{uvw}]_{\mathrm{bar}}$ $-[\mathrm{uvw}]_{\mathrm{cel}} /[\mathrm{uvw}]_{\mathrm{cel}}$, between [100] and [010] directions, is 0.06 and 0.02 , respectively. These values are the highest possible mismatches; for nucleation of intermediate compositions of the $(\mathrm{Ba}, \mathrm{Sr}) \mathrm{SO}_{4}$ solid solution on barite (001), the mismatch is always 
smaller. According to Walton (1969) the distortion of the lattice of the depositing phase can be overcome by elastic deformation. For small degrees of mismatch, the interface accommodates itself by strain. The maximum mismatch values calculated for the case of $(\mathrm{Ba}, \mathrm{Sr}) \mathrm{SO}_{4}$ barite (001) interface are quite small and elastic accommodation of the initial nuclei on the surface seems to be likely. In such a situation an influence of the substrate on the shape of the nuclei can be expected. This explains the observation that at the beginning of the nucleation process two-dimensional islands have a characteristic ellipsoidal shape. Ellipsoidal morphologies minimise the interfacial energy and are typical for coherent nucleation. The subsequent growth of the islands with a very low lateral spreading rate also is indicative of the interfacial strain. As the islands increase in height, the new layers are accommodated without additional strain and the effect of the substrate can be considered negligible. This is reflected in the change of the two-dimensional island morphology, which begins to develop polyhedral shapes defined by the forms (001) and $\{210\}$. However, before the two-dimensional islands acquire sufficient layers to develop the final polyhedral morphology, it is common to observe the formation of vicinal faces in the central part of the two-dimensional islands (Fig. 6b). This occurs at an early stage of growth and is another way of accommodating the elastic stress at the interface.

The structural control of the two-dimensional nucleation distribution described above, together with the possibility of having different growth mechanisms operating simultaneously for different compositional ranges of a solid solution on the same surface can provide an explanation for a phenomenon known as intrasectoral zoning (Paquette and Reeder, 1990) in which chemical inhomogeneities develop on crystal surfaces grown simultaneously from a fluid phase.

\section{Conclusion}

This work has shown that the crystallisation behaviour of $(\mathrm{Ba}, \mathrm{Sr}) \mathrm{SO}_{4}$ solid solution from aqueous solutions is determined by the interrelation between supersaturation, growth mechanisms and structural control of the substrate. Moreover, the differences in nucleation kinetics as a function of the solid composition (the nucleation rate function) allow a qualitative interpretation of the relative composition of the newly grown surfaces. It seems clear that the evaluation of these factors is essential for a better understanding of the crystallisation in SS-AS systems and can be relevant to interpret and predict actual distribution coefficients.

\section{Acknowledgements}

C.M.P. acknowledges the receipt of a Marie Curie Fellowship from the European Commission and A.P the receipt of a grant (PU 153/1-2) from the Deutsche Forschungsgemeinschaft (DFG). We thank Peter Risthaus and Dirk Bosbach for pre-publication access to the data on celestite nucleation kinetics, and Udo Becker for calculated activity-composition relation. Computer codes for calculating supersaturation were kindly provided by M. Prieto.

\section{References}

Allison, J.D., Brown, D.S., Novo-Gradac, K.J., 1991. MINTEQA2/PRODEFA2, a geochemical assessment model for environmental systems: Version 3.0 User's Manual EPA/600/3-91/021.

Becker, U., Fernández-González, A., Prieto, M., Harrison, R., Putnis, A., 1999. Direct calculation of thermodynamic properties of the barite/celestite solid solution from molecular principles. submitted to Physics and Chemistry of Minerals.

Bosbach, D., Hall, C., Putnis, A., 1998. Mineral precipitation and dissolution in aqueous solution: in-situ microscopic observations on barite (001) with atomic force microscopy. Chem. Geol. 151, 143-160.

Blount, C.W., 1977. Barite solubilities and thermodynamic quantities up to $300^{\circ} \mathrm{C}$ and 1400 bars. Am. Mineral. 62, 942-957.

Blundy, J., Wood, B., 1994. Prediction of crystal-melt partition coefficients from elastic moduli. Nature 372, 452-454.

Broecker, W.S., Peng, T.-H., 1982. Tracers in the Sea. LamontDoherty Geological Observatory, NY.

Brower, E., Renault, J., 1971. Solubility and enthalpy of the barium-strontium sulfate solid solution series. New Mexico State Bureau of Mines and Mineral Resources. Circular No. 116.

Chernov, A.A., 1984. In: Modern Crystallography III (Ccrystal Growth). Springr Verlag, pp. 48-98.

Davis, J.A., Fuller, C.C., Cook, A.D., 1987. A model for trace metal sorption processes at the calcite surface: adsorption of $\mathrm{Cd}^{2+}$ and subsequent solid solution formation. Geochim. Cosmochim. Acta 51, 1477-1490. 
Delaney, M.L., Boyle, A.B., 1987. Cd/Ca in late Miocene benthic foraminifera and changes in the global organic carbon budget. Nature 300, 156-159.

Experimental trace element geochemistry: Proceedings of an international conference held in Sedona, Arizona. Drake, M.J., Holloway, J.R. (Eds.), Geochim. Cosmochim. Acta 42.

Dudley, L.M., Mclean, J.E., Sims, R.C., Jurinak, J.J., 1988. Sorption of copper and cadmium from the water soluble fraction of an acid mine waste by two calcareous soils. Soil Sci. 145, 207-214.

Glynn, P.D., Reardon, E.J., 1990. Solid-solution aqueous solution equilibria: thermodynamic theory and representation. Am. J. Sci. 290, 164-201.

Goldsmith, J.R., 1959. Some aspects of the geochemistry of carbonates. In: Abelson, P.H. (Ed.), Research in Geochemistry. Wiley, NY, pp. 336-358.

Goldstein, J.I., Newbury, D.E., Echlin, P., Joy, D.C., 1992. ISBN: 0-306-44175-6Scanning Electron Microscopy and X-Ray Microanalysis: A Text for Biologists, Materials Scientists, and Geologists. Plenum.

Hanor, J.S., 1968. Frequency distribution of composition in the barite-celestite series. Am. Mineral. 53, 1215-1222.

Kastner, M., Siever, R., 1979. Low temperature feldespars in sedimentary rocks. Am. J. Sci. 279, 435-479.

Lippmann, F., 1980. Phase diagrams despicting aqueous solubility of binary carbonate systems. N. Jb. Mineral. Abh. 139, 1-25.

Lorens, R.B., 1980. Sr, Mn and Co distribution coefficients in calcite as a function of the precipitation rate. Geochim. Cosmochim. Acta 45, 553-561.

Malinin, S.D., Urusov, V.S., 1983. The experimental and theoretical data on isomorphism in the $(\mathrm{Ba}, \mathrm{Sr}) \mathrm{SO}_{4}$ system in relation to barite formation. Geokhimiya 9, 1324-1334.

Nielsen, A.E., Sohnel, O., 1971. Interfacial tensions electrolyte crystal-aqueous solution from nucleation data. J. Cryst. Growth 11, 233-242.

Paquette, J., Reeder, R., 1990. New type of compositional zoning in calcite: Insights into crystal growth mechanisms. Geology $18,1244-1247$.

Paquette, J., Reeder, R., 1994. Relationship bewtween surface structure, growth mechanism, and trace incorporation in calcite. Geochim. Cosmochim. Acta 59, 735-749.

Pingitore, N.E., 1978. The behaviour of $\mathrm{Zn}^{2+}$ and $\mathrm{Mn}^{2+}$ during carbonate diagenesis: theory and applications. J. Sediment. Petrol. 48, 799-814.

Pina, C.M., Becker, U., Risthaus, P., Bosbach, D., Putnis, A., 1998a. Molecular-scale mechanisms of crystal growth in barite. Nature 395, 483-486.

Pina, C.M., Bosbach, D., Prieto, M., Putnis, A., 1998b. Microtopography of the barite (001) face during growth: AFM observations and PBC theory. J. Cryst. Growth 187, 119-125.

Plummer, L.M., Busenberg, E., 1987. Termodynamics of aragonite-strontianite solid solutions: Results from stoichiometric solubility at 25 and $76^{\circ} \mathrm{C}$. Geochim. Cosmochim. Acta 51, 1393-1411.

Prieto, M., Putnis, A., Fernández-Díaz, L., 1993. Crystallization of solid solutions from aqueous solutions in a porous medium: Zoning in (BaSr)SO ${ }_{4}$. Geol. Mag. 130, 289-299.
Prieto, M., Fernández-Díaz, L., López-Andrés, S., 1994. Metastability in diffusing-reacting systems. J. Cryst. Growth 108, 770-778.

Prieto, M., Fernández-González, A., Putnis, A., Fernández-Díaz, L., 1997. Nucleation, growth and zoning phenomena in crystallizing $(\mathrm{Ba}, \mathrm{Sr}) \mathrm{CO}_{3}, \mathrm{Ba}\left(\mathrm{SO}_{4}, \mathrm{CrO}_{4}\right),(\mathrm{Ba}, \mathrm{Sr}) \mathrm{SO}_{4}$, and $(\mathrm{Cd}$, $\mathrm{Ca}) \mathrm{CO}_{3}$ solid solutions from aqueous solutions. Geochim. Cosmochim. Acta 61, 3383-3397.

Putnis, A., Fernández-Díaz, L., Prieto, M., 1992. Experimentally produced oscillatory zoning in the $(\mathrm{BaSr}) \mathrm{SO}_{4}$ solid solution. Nature 358, 743-745.

Putnis, A., Prieto, M., Bosbach, D., 1997. The sorption of $\mathrm{Cd}^{2+}$ in aqueous solution on calcite surfaces - adsorption, partitioning or precipitation? In: Abstracts EUG 9 No. 1. Terra Nova vol. 9.

Putnis, A., Prieto, M., Fernández-Díaz, L., 1995. Fluid supersaturation and crystallisation in porous media. Geol. Mag. 132, $1-13$.

Reardon, E.J., Armstrong, D.K., 1987. Celestite $\left(\mathrm{SrSO}_{4}(\mathrm{~s})\right)$ solubility in water, sea water and $\mathrm{NaCl}$ solution. Geochim. Cosmochim. Acta 51, 63-72.

Redlich, O., Kister, A.T., 1948. Algebraic representation of thermodynamic properties and the clasification of solutions: industrial and engineering chemistry. 40 2, 345-348.

Risthaus, P., Pina, C.M., Bosbach, D., Becker, U., Putnis, A., 1998. Zweidimensionale Keimbildung auf \{001\}und \{210\}Flächen der Sulfatminerale mit Barytstruktur: in-situ AFM-Untersuchungen. Berichte der Deutschen Mineralogischen Gesellschaft 10, 237.

Simon, B., Boistelle, R., 1981. Crystal: growth from low temperature solutions. J. Cryst. Growth 52, 779-781.

Sposito, G., 1986. Distinguishing adsorption from surface precipitation. In: Davis, J.A., Hayes, K.F. (Eds.), Geochemical Processes of Mineral Surfaces. ACS Symposium Series 323, pp. 217-228.

Söhnel, O., 1982. Electrolyte crystal-aqueous solution interfacial tensions from crystallisation data. J. Cryst. Growth 57, 101108.

Sunagawa, I., 1984. Growth of crystal in nature. In: Sunagawa, I. (Ed.), Materials science of the earth's interior. TERRAPUB, Tokyo.

Sverjensky, D.A., 1985. The distribution of divalent trace elements between sulfides, oxides, silicates and hydrothermal solutions: I. Thermodynamic basis. Geochim. Cosmochim. Acta 49, 853-864.

Tesoriero, A.J., Pankow, J.F., 1996. Solid solution partitioning of $\mathrm{Sr}^{2+}, \mathrm{Ba}^{2+}$ and $\mathrm{Cd}^{2+}$ to calcite. Geochim. Cosmochim. Acta 60, 1053-1063.

Walton, A.G., 1969. Nucleation in liquids and solutions. In: Zettlemoyer (Ed.), Nucleation. Marcel Dekker, NY, pp. 225307.

Zachara, J.M., Cowan, C.E., Resch, C.T., 1991. Sorption of divalent metals on calcite. Geochim. Cosmochim. Acta 55, 1549-1562. 